\title{
Engineering the elastic modulus of NiTi cellular structures fabricated by selective laser melting
}

\author{
F. Bartolomeu ${ }^{\text {a, }}$, M.M. Costa ${ }^{\text {a }}$, N. Alves $^{\mathrm{b}}$, G. Miranda ${ }^{\mathrm{a}}$, F.S. Silva ${ }^{\mathrm{a}}$ \\ ${ }^{\text {a }}$ Center for MicroElectroMechanical Systems (CMEMS-UMinho), University of Minho, Campus de Azurém, 4800-058, Guimarães, Portugal \\ ${ }^{\mathrm{b}}$ Centre for Rapid and Sustainable Product Development Polytechnic Institute of Leiria, Rua General Norton de Matos, Apartado 4133, 2411-901, Leiria, Portugal
}

\section{A R T I C L E I N F O}

\section{Keywords:}

NiTi

Power bed fusion

Selective laser melting

Cellular structures

Elastic modulus

\begin{abstract}
A B S T R A C T
Nickel-titanium (NiTi) cellular structures are a very promising solution to some issues related to orthopaedic implant failure. These structures can be designed and fabricated to simultaneously address a combination of mechanical and physical properties, such as elastic modulus, porosity, wear and corrosion resistance, biocompatibility and appropriate biological environment. This ability can enhance the modest interaction currently existing between metallic dense implants and surrounding bone tissue, allowing long-term successful orthopaedic implants. For that purpose, NiTi cellular structures with different levels of porosity intended to reduce the elastic modulus were designed, modelled, selective laser melting (SLM) fabricated and characterized. Significant differences were found between the CAD design and the SLM-produced NiTi structures by performing systematic image analysis. This work proposes designing guidelines to anticipate and correct the systematic differences between CAD and produced structures. Compressive tests were carried out to estimate the elastic modulus of the produced structures and finite element analyses were performed, for comparison purposes. Linear correlations were found for the dimensions, porosity, and elastic modulus when comparing the CAD design with the SLM structures. The produced NiTi structures exhibit elastic moduli that match that of bone tissue, which is a good indication of the potential of these structures in orthopaedic implants.
\end{abstract}

\section{Introduction}

The fabrication of biomedical porous materials for orthopaedic implants is in great demand due to their capability to simultaneously provide adequate mechanical properties (e.g. stiffness) and a suitable biological environment for cell seeding (Wang et al., 2016; Van Hooreweder et al., 2017). Moreover, by using 3D data from tomography, each patient's anatomy can be considered to design structured implants suited to the host bone (Chen and Thouas, 2015; Yan et al., 2015; Ryan et al., 2006; Thavornyutikarn et al., 2014). The desired porosity and elastic modulus (physical and mechanical properties) and the outcome biological properties can be obtained by selecting adequate biomaterials and by controlling the architecture of the porous structures, such as pore size; wall thickness; and the shape, interconnection, and volume fraction of the pores (Van Bael et al., 2012).

Ti6Al4V alloy has been the main choice for dental and orthopaedic implants due to its mechanical strength, corrosion resistance and biological compatibility (Zhang et al., 2014; Bartolomeu et al., 2016; Arabnejad et al., 2016; Moura et al., 2019; Toptan et al., 2019). However, these implants do fail and bone resorption around the implant habitually occurs. Typically, 10-15 years after total hip arthroplasty, critical bone resorption leads to the need for revision surgeries (Holzwarth and Cotogno, 2012; Bartolomeu et al., 2018a). Implant failure is mostly correlated to three aspects, the high elastic modulus $(\approx 110 \mathrm{GPa})$ compared to cortical bone tissue (10-30 GPa) (Bartolomeu et al., 2018b; Rahimizadeh et al., 2018), the poor wear resistance of this alloy (Bose et al., 2018; Bartolomeu et al., 2019a; Moura et al., 2017) and non-uniform contact between the implant and the nearby cortical bone, leading to deficient stress transmission/distribution, causing bone resorption.

Nickel-titanium (NiTi) alloy has been widely used in the robotics, electrical, civil, automotive, aerospace and medical industries due to this alloy's multifunctional properties (Hamilton et al., 2017). Usually referred as the workhorse of shape memory alloys, NiTi's properties such as shape memory effect (SME); superelasticity; large recovery strain; high strength; fatigue, wear and corrosion resistance; and biocompatibility make this alloy appealing for many engineering applications (Zhou et al., 2019; Speirs et al., 2017; Dadbakhsh et al., 2015).

\footnotetext{
* Corresponding author.

E-mail address: flaviojorgebartolomeu@gmail.com (F. Bartolomeu).
} 


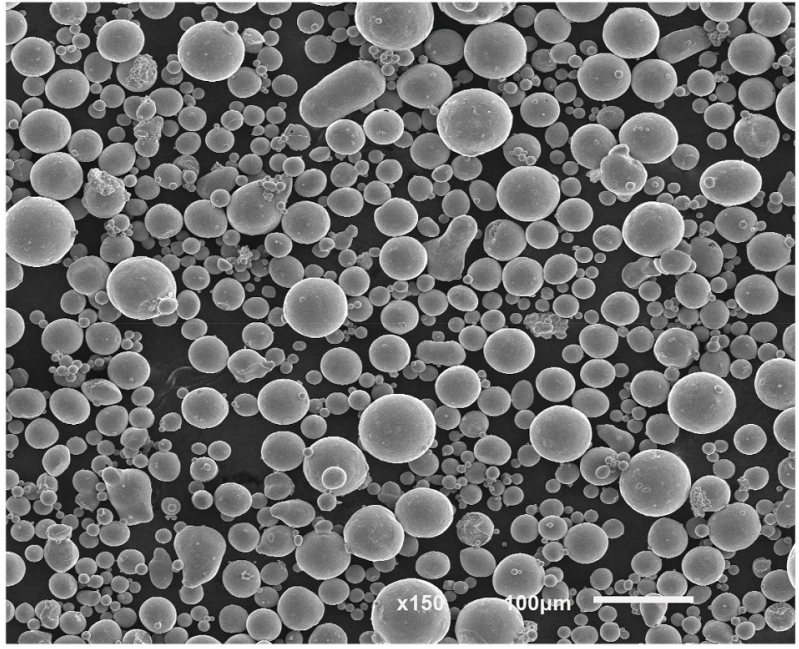

Fig. 1. SEM image of NiTi powder.

NiTi cellular structures can be used to improve some implant failure related issues. First, NiTi's higher wear resistance compared to Ti6Al4V (Elahinia et al., 2012) can help reduce the release of wear debris that is extremely detrimental to biological tissues. Second, the well-organized NiTi cellular structure can lower the elastic modulus mismatch between the implant and bone (Bose et al., 2018; Chen et al., 2017; Fousová et al., 2017; Capek et al., 2016; Zhang and Wei, 2019). As an example, Andani et al. (Taheri et al., 2017) used selective laser melting (SLM) to produce NiTi lattice structures with different levels of porosity showing elastic modulus close to that of cortical bone. Finally, NiTi cellular structures can be designed to be an integrating part of an active implant, capable of promoting uniform contact between implant and bone by using SME.

Manufacturing NiTi alloys via conventional processing techniques is rather challenging mainly due to NiTi's high work hardening, toughness and ductility (Behavior and Melting, 1109). Machining causes severe tool wear and conventional high-temperature methods, such as casting, can result in increasing impurity (Oxygen, Carbon, Nitrogen) contents, consequently hindering the functional properties of NiTi, like SME (Elahinia et al., 2012). Moreover, traditional processing routes do not allow the production of engineered/structured materials. Additive manufacturing processes like SLM are very appealing since, by being a layer-by-layer technique, they are capable of fabricating complex structures based on CAD data (Bartolomeu et al., 2018a, 2019a; Buciumeanu et al., 2018). As a powder bed fusion technique, SLM's high design freedom allows the fabrication of complex and customized cellular structures that can potentiate innovative solutions for orthopaedic implants (Bartolomeu et al., 2019a).

SLM's capability of fabricating structured materials, especially having thin-walled features (Miranda et al., 2019), is limited once significant differences (dimensional and geometrical (Bartolomeu et al., 2019b)) are persistently found between CAD data and the manufactured
SLM cellular structures (Yan et al., 2015; Zhang et al., 2014; Arabnejad et al., 2016; Ran et al., 2018; Attar et al., 2015; Bartolomeu et al., 2020). Considering that these structures are designed to match specific physical, mechanical and biological properties, these deviations can be critical. In this work, six different NiTi cellular structures were designed, SLM fabricated and characterized. Morphological, physical, chemical, microstructural, thermal and mechanical analyses were performed on these structures. Finite element analysis (FEA) and experimental results were also used to propose engineering tools to anticipate SLM production's inherent deviations.

\section{Materials and methods}

\subsection{Materials and SLM fabrication details}

A $\mathrm{Ni}_{50.8} \mathrm{Ti}_{49.2}$ ingot (at.\%) obtained from SAES Smart Materials (USA) was atomized to powder by TLS Technique GmbH (Germany) using the electrode induction-melting gas atomization (EIGA) technique. Fig. 1 depicts the morphology of the powder (D10 of $34.64 \mu \mathrm{m}$, D50 of $47.5 \mu \mathrm{m}$ and D90 of $62.94 \mu \mathrm{m}$ ) used to fabricate the NiTi structures.

Few groups around the world have been capable of producing highquality NiTi parts by SLM, mainly due to the challenges that this alloy presents. In fact, for NiTi SLM fabrication, several aspects must be controlled, such as NiTi powder quality and suitable SLM processing parameters, to obtain parts mainly composed of an NiTi phase that presents a low level of defects.

In this study, NiTi structures were produced using a 125HL SLM Solutions equipment with a $400 \mathrm{~W}$ Yb-fiber laser having an $87 \mu \mathrm{m}$ diameter. An argon atmosphere was provided during fabrication and the specimens grow up in a platform at $200{ }^{\circ} \mathrm{C}$. A $90 \mathrm{~W}$ laser power, 600 $\mathrm{mm} / \mathrm{s}$ scan speed, $90 \mu \mathrm{m}$ scan spacing and $30 \mu \mathrm{m}$ layer thickness were used as the laser parameters. A $55.6 \mathrm{~J} / \mathrm{mm}^{3}$ input energy was employed using this set of parameters. This energy is completely aligned with that used in studies found in the literature regarding NiTi SLM fabrication (Hamilton et al., 2017; Elahinia et al., 2012; Taheri et al., 2017; Jahadakbar et al.; Yang et al., 2019; Liu and Shin, 2019).

\subsection{Study design}

In this study, NiTi cellular structures were designed, fabricated and characterized, targeting the fabrication of orthopaedic implants. In this sense, several design aspects should be considered to lower the elastic modulus to values close to that of bone. Open-cell and wall sizes, opencell architecture and orientation, and open-cell interconnectivity are some of these parameters. Cubic-like NiTi structures were modelled with porosities greater than $50 \%$, wall sizes greater than or equal to $100 \mu \mathrm{m}$ (since the laser spot of the equipment is $87 \mu \mathrm{m}$ ) and open-cell sizes, 500 and $600 \mu \mathrm{m}$ (Arabnejad et al., 2016; Karageorgiou and Kaplan, 2005; Kumar et al., 2016), suitable for bone ingrowth. Table 1 shows the CAD model design details, including the open-cell and wall sizes and the porosity.

Table 1

Model CAD design details.

\begin{tabular}{|c|c|c|c|c|c|c|}
\hline Structure & SP1 & SP2 & SP3 & SP4 & SP5 & SP6 \\
\hline Open-cell $(\mu \mathrm{m})$ & 500 & 600 & 500 & 600 & 500 & 600 \\
\hline Wall $(\mu \mathrm{m})$ & 300 & 300 & 150 & 150 & 100 & 100 \\
\hline Porosity (\%) & 65.2 & 71.8 & 83.3 & 87.0 & 90.7 & 92.3 \\
\hline Mode CAD desig & & & & & & \\
\hline
\end{tabular}



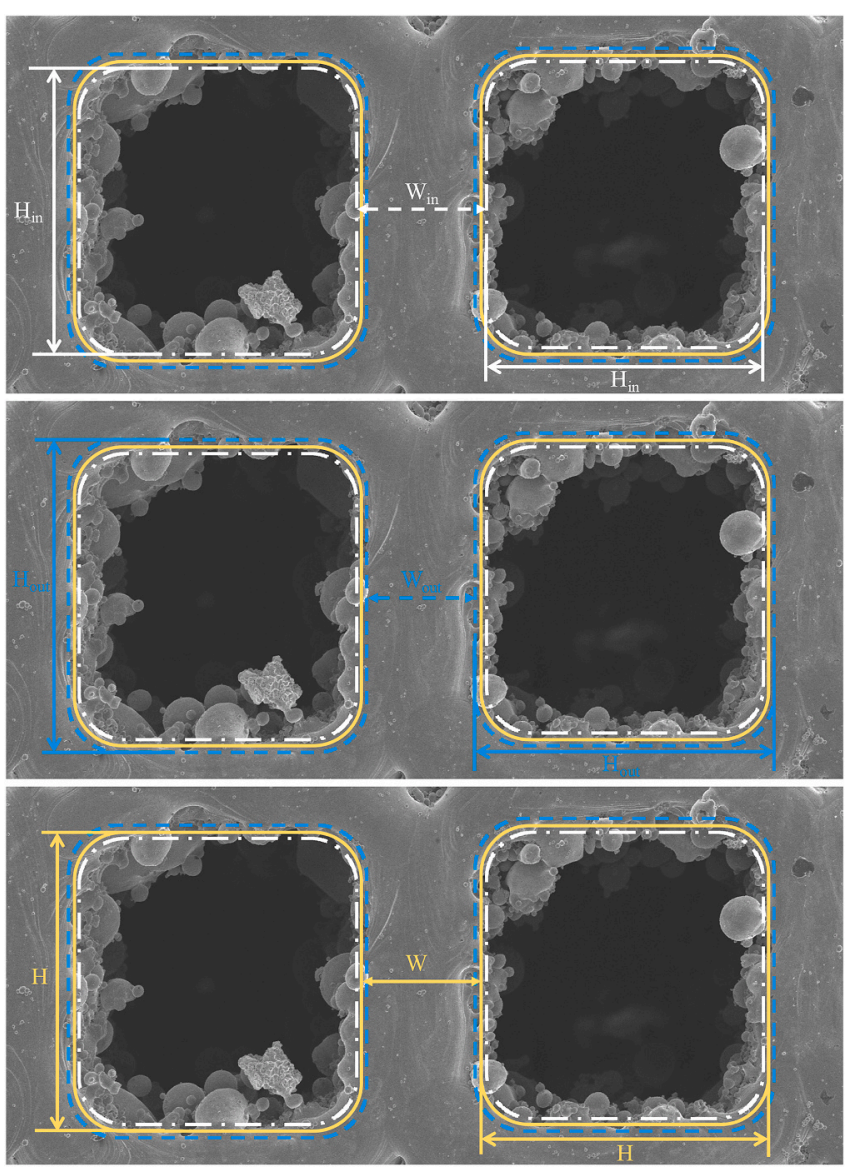

Fig. 2. Methodology adopted to perform the measurements of the open-cell and wall dimensions.

\subsection{Morphological analysis and porosity measurements}

Scanning electron microscopy (SEM, FEI Nova 200) was carried out to obtain SEM images for all the NiTi cellular structures, acquiring isometric and top views of these structures, as seen in Figs. 4 and 5. Energydispersive X-ray spectroscopy (EDS) analyses were also performed on the SLM NiTi structures.

A quantitative morphological study was also performed by systematically measuring the open-cell and wall (distance between two consecutive open-cells) dimensions. Surface images of the produced specimens were used as input data and Adobe Photoshop was used to perform this analysis. Fig. 2 shows the methodology used to obtain the open-cell (H) and wall (W) dimensions. For each group (SP1 to SP6), the average dimensions were obtained from a total of 60 measurements made in two different images from two different specimens.

The parameters $\mathrm{H}_{\text {in }}$ and $\mathrm{H}_{\text {out }}$ were measured as the inner and the outer dimensions of the open-cells and, using the same rationale, $\mathrm{W}_{\mathrm{in}}$ and $\mathrm{W}_{\text {out }}$ were also measured as the distance between two consecutive $\mathrm{H}_{\text {in }}$ and $\mathrm{H}_{\text {out }}$, respectively. After performing the measurement, $\mathrm{H}$ was calculated as the average of $\mathrm{H}_{\text {in }}$ and $\mathrm{H}_{\text {out }}$. Similarly, W was calculated as the average of $\mathrm{W}_{\text {in }}$ and $\mathrm{W}_{\text {out }}$.

In order to determine the porosity, four structures for each condition (SP1 to SP6) were used for measuring their mass and volume and considering the theoretical density of NiTi. After assessing the differences between the CAD model and the SLM produced structures, new CAD designs (hereafter named adjusted CAD designs) were created, aiming to reproduce the real dimensions and geometries of the produced structures.
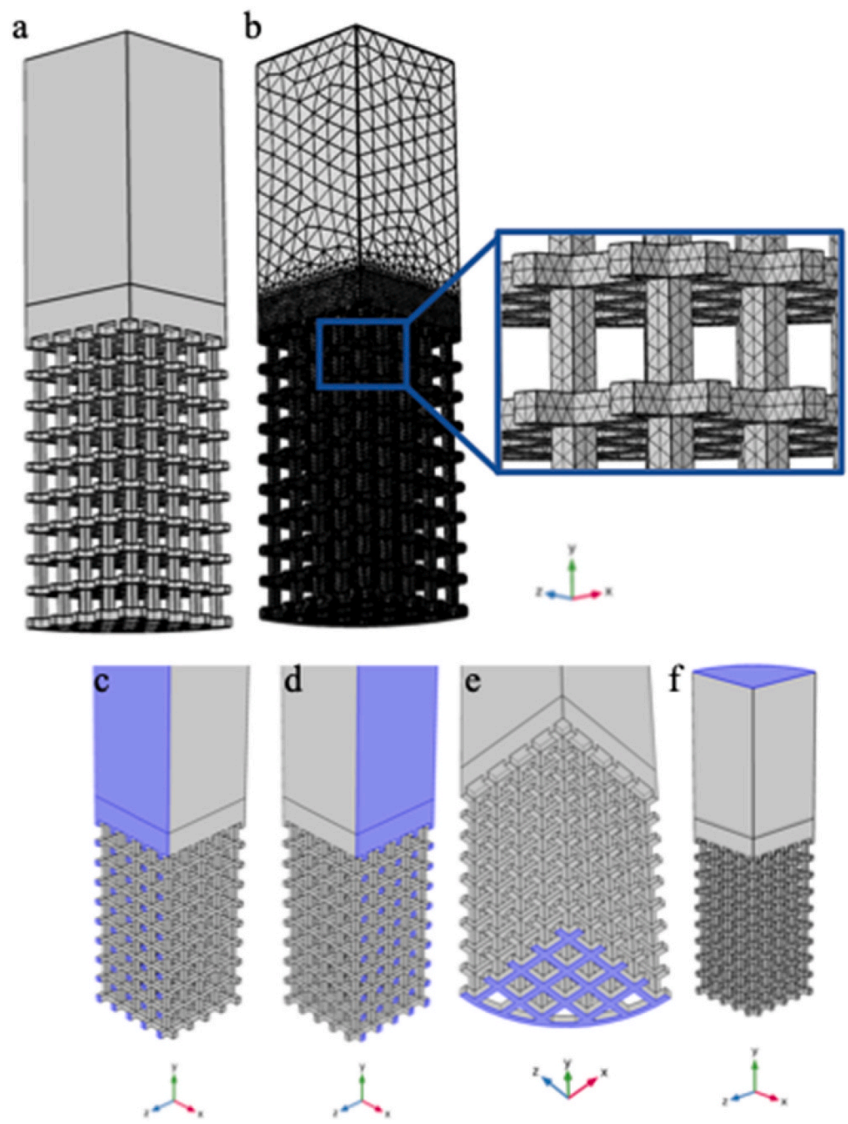

Fig. 3. Finite element analysis details: (a) model; (b) mesh grid; prescribed displacements (c) $\mathrm{u}_{0 \mathrm{x}}=0$ (d) $\mathrm{u}_{0 \mathrm{z}}=0$; (e) $\mathrm{u}_{0 \mathrm{y}}=0$ and (f) boundary load.

\subsection{X-ray diffraction and DSC analysis}

X-ray diffraction data were collected from $10^{\circ}$ to $90^{\circ} 2 \theta$, with a $0.05^{\circ}$ step size and $1 \mathrm{~s} /$ step counting time, using a Bruker AXS D8 Discover (USA) and performed at room temperature. Differential Scanning Calorimetry (DSC) analyses were performed using a DSC Q20 (TA Instruments) using a $10{ }^{\circ} \mathrm{C} / \mathrm{min}$ heating/cooling rate under a nitrogen atmosphere. These analyses were carried out for the NiTi bar (used for the powder atomization), the NiTi powder and the SLM NiTi specimens.

\subsection{Mechanical testing and numerical analysis}

Compressive tests were performed using a universal servo-hydraulic testing equipment (Instron 8874, USA) at room temperature according to ISO 13314. Four specimens were tested for each group. The load gauge of the equipment was used for load signal acquisition. Tests were performed with a $0.005 \mathrm{~mm} / \mathrm{s}$ crosshead speed and the strain signal was obtained using a dynamic extensometer from Instron (model 2620-601). Vickers hardness tests were performed using a DuraScan equipment from EMCO-TEST Company, with a load of $3 \mathrm{~N}$ during $15 \mathrm{~s}$. The obtained results are an average of five indentations per specimen.

FEA software was used to simulate compression stress-strain tests. A structural mechanical module was set for the mechanical simulation and the structures were modelled as a linear elastic material (NiTi) with a 37 GPa elastic modulus, 0.3 Poisson's ratio and $6500 \mathrm{~kg} / \mathrm{m}^{3}$ density (Jahadakbar et al.). Tetrahedral elements were used for both the model CAD and the adjusted CAD simulations. Fig. 3 shows the FEA details. 

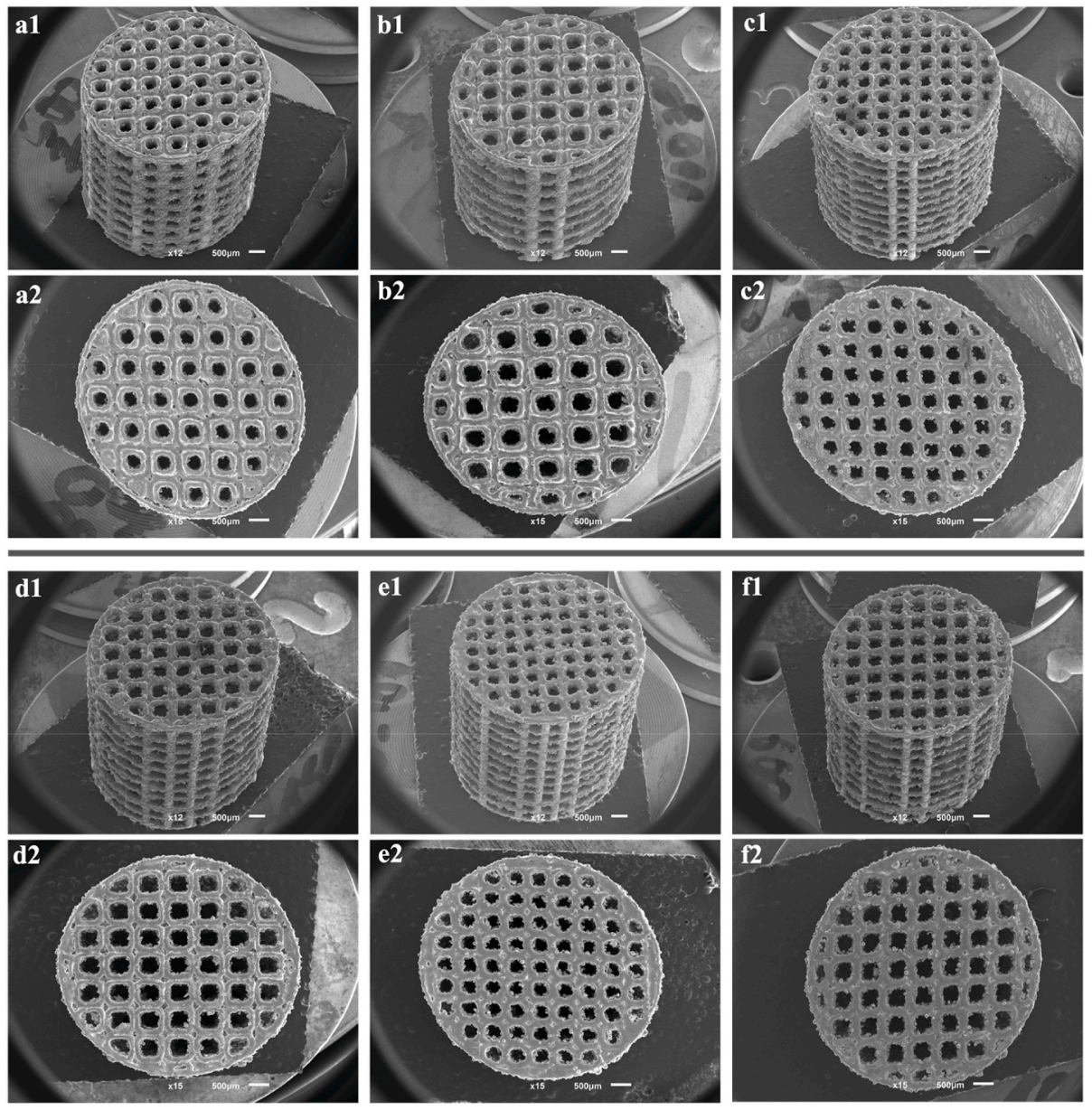

Fig. 4. SEM images of the NiTi structures as produced: (a) SP1; (b) SP2; (c) SP3; (d) SP4; (e) SP5 and (f) SP6.
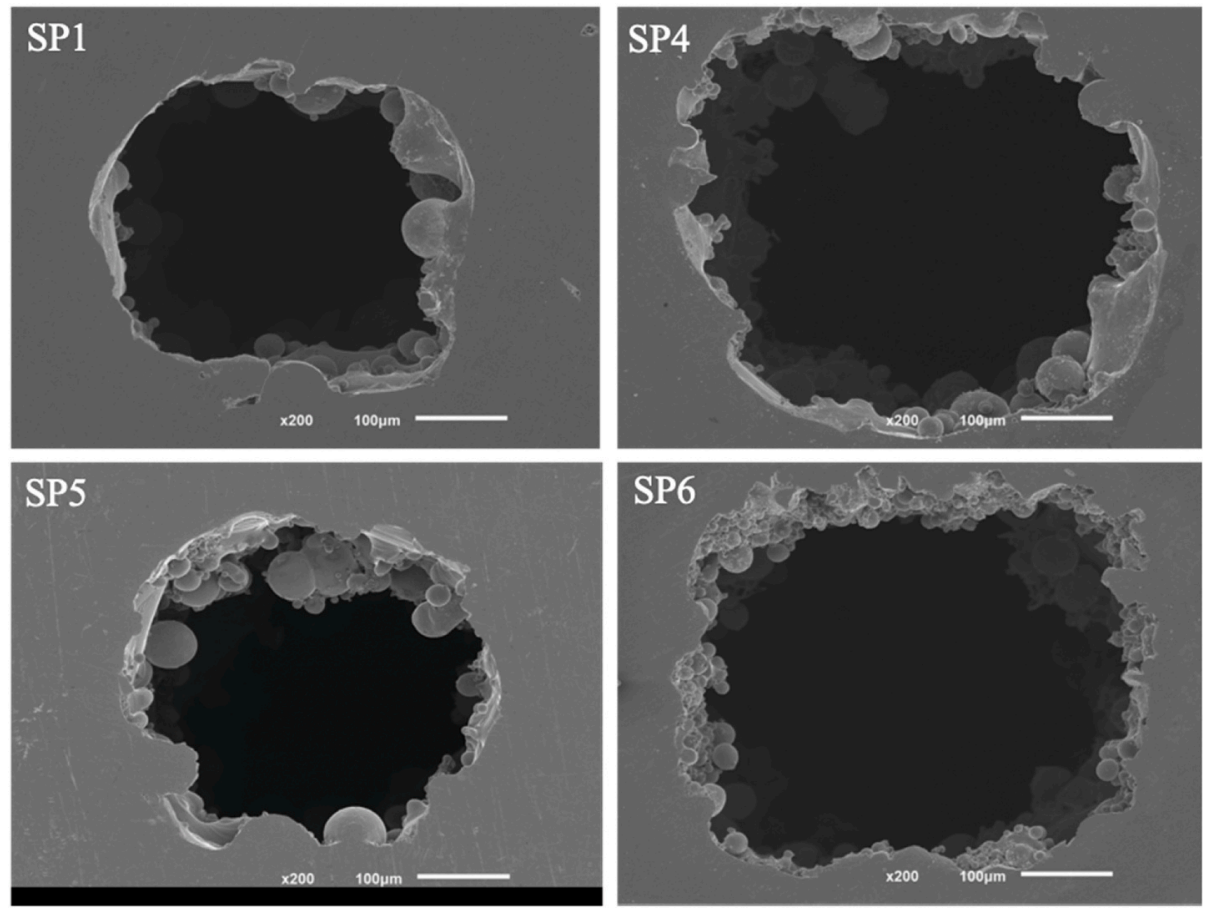

Fig. 5. Top view SEM images of the NiTi structures after polished for different open-cell and wall sizes. 

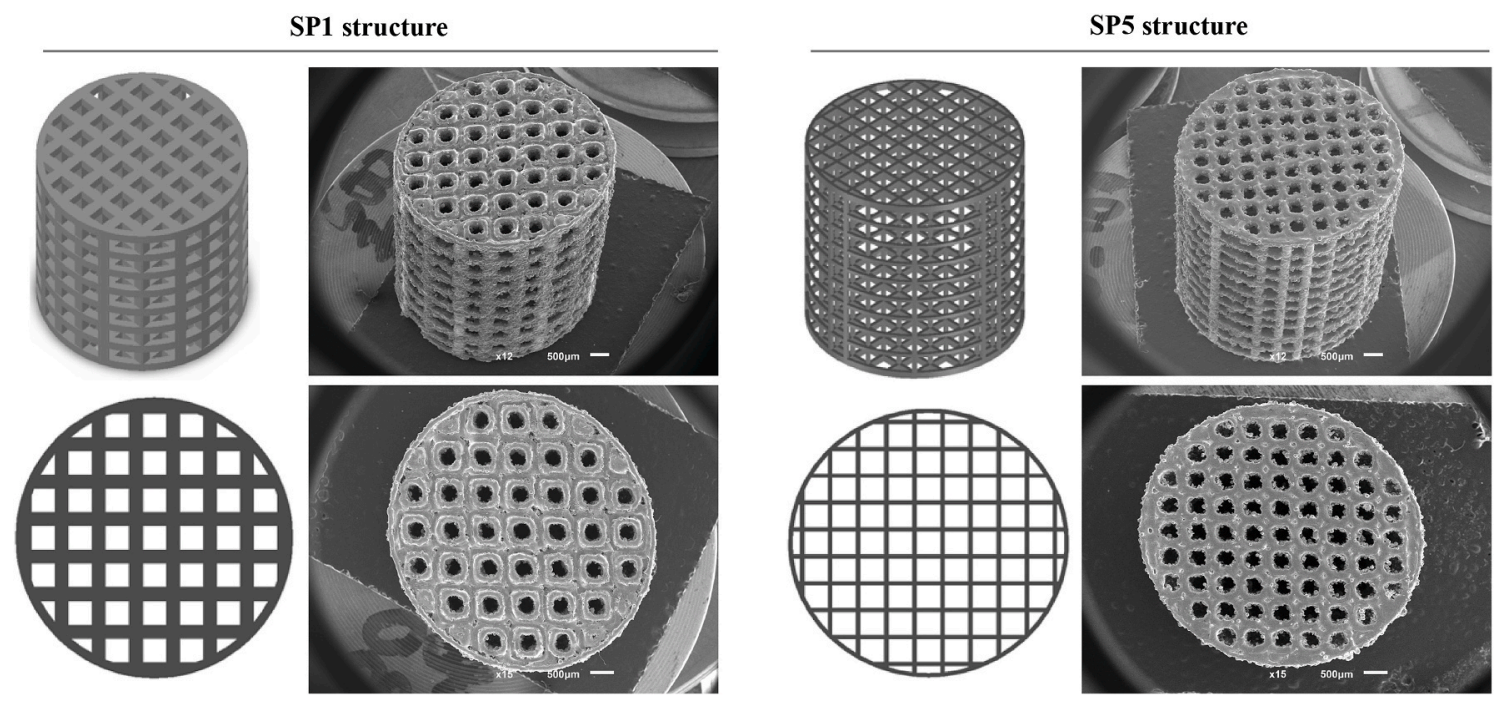

Fig. 6. Comparison between model CAD and the SLM structures (SP1 and SP5).

Table 2

Comparison between the Model CAD details and the SLM structures measurements.

\begin{tabular}{|c|c|c|c|c|c|c|}
\hline \multirow[t]{2}{*}{ Structure } & \multicolumn{3}{|c|}{ Model CAD details } & \multicolumn{3}{|c|}{ Produced structures measurements } \\
\hline & $\begin{array}{l}\text { Open- } \\
\text { cell size } \\
(\mu \mathrm{m})\end{array}$ & $\begin{array}{l}\text { Wall } \\
\text { size } \\
(\mu \mathrm{m})\end{array}$ & $\begin{array}{l}\text { Porosity } \\
(\%)\end{array}$ & $\begin{array}{l}\text { Open- } \\
\text { cells size } \\
(\mu \mathrm{m})\end{array}$ & $\begin{array}{l}\text { Walls } \\
\text { size } \\
(\mu \mathrm{m})\end{array}$ & $\begin{array}{l}\text { Porosity } \\
(\%)\end{array}$ \\
\hline SP1 & 500 & 300 & 65.2 & $\begin{array}{l}391.3 \pm \\
13.9\end{array}$ & $\begin{array}{l}391.6 \\
\pm 11.1\end{array}$ & $\begin{array}{l}44.3 \pm \\
0.8\end{array}$ \\
\hline SP2 & 600 & 300 & 71.8 & $\begin{array}{l}493.4 \pm \\
9.1\end{array}$ & $\begin{array}{l}405.1 \\
\pm 13.4\end{array}$ & $\begin{array}{l}59.9 \pm \\
0.8\end{array}$ \\
\hline SP3 & 500 & 150 & 83.3 & $\begin{array}{l}387.8 \pm \\
7.3\end{array}$ & $\begin{array}{l}247.7 \\
\pm 9.2\end{array}$ & $\begin{array}{l}68.4 \pm \\
0.5\end{array}$ \\
\hline SP4 & 600 & 150 & 87.0 & $\begin{array}{l}495.0 \pm \\
4.6\end{array}$ & $\begin{array}{l}251.8 \\
\pm 9.6\end{array}$ & $\begin{array}{l}72.7 \pm \\
0.6\end{array}$ \\
\hline SP5 & 500 & 100 & 90.7 & $\begin{array}{l}387.2 \pm \\
7.3\end{array}$ & $\begin{array}{l}208.3 \\
\pm 12.2\end{array}$ & $\begin{array}{l}73.9 \pm \\
0.3\end{array}$ \\
\hline SP6 & 600 & 100 & 92.3 & $\begin{array}{l}491.8 \pm \\
9.7\end{array}$ & $\begin{array}{l}205.8 \\
\pm 7.6\end{array}$ & $\begin{array}{l}78.1 \pm \\
0.4\end{array}$ \\
\hline
\end{tabular}

\section{Results and discussion}

\subsection{Characterization of the as-produced structures}

\subsubsection{Morphological analysis and porosity assessment}

In this study, the SLM process was exploited to produce NiTi cellular structures with different porosity levels. Six types of NiTi cellular structures were designed, SLM produced and characterized. Fig. 4 depicts SEM images of the as-produced structures with isometric and top views. Fig. 4 (a) shows the SP1 NiTi structure with the lowest CAD porosity, 65.2\%, while Fig. 4 (f) shows SP6 NiTi structure with the highest CAD porosity, $92.3 \%$ (see Table 1). Fig. 5 shows top-views SEM images of the NiTi structures after polishing, showing the absent of defects or residual porosity in the dense regions of the parts (walls of the structures).

For all the NiTi structures (SP1 to SP6), non-negligible differences in the dimensions were detected between the SLM produced structures and the CAD model, for both the open-cells and the walls. These differences can be easily perceived by analysing Fig. 6 , which shows the SP1 and SP5 CAD models and the corresponding SLM produced structures. Table 2 shows the average \pm standard deviation values measured on the

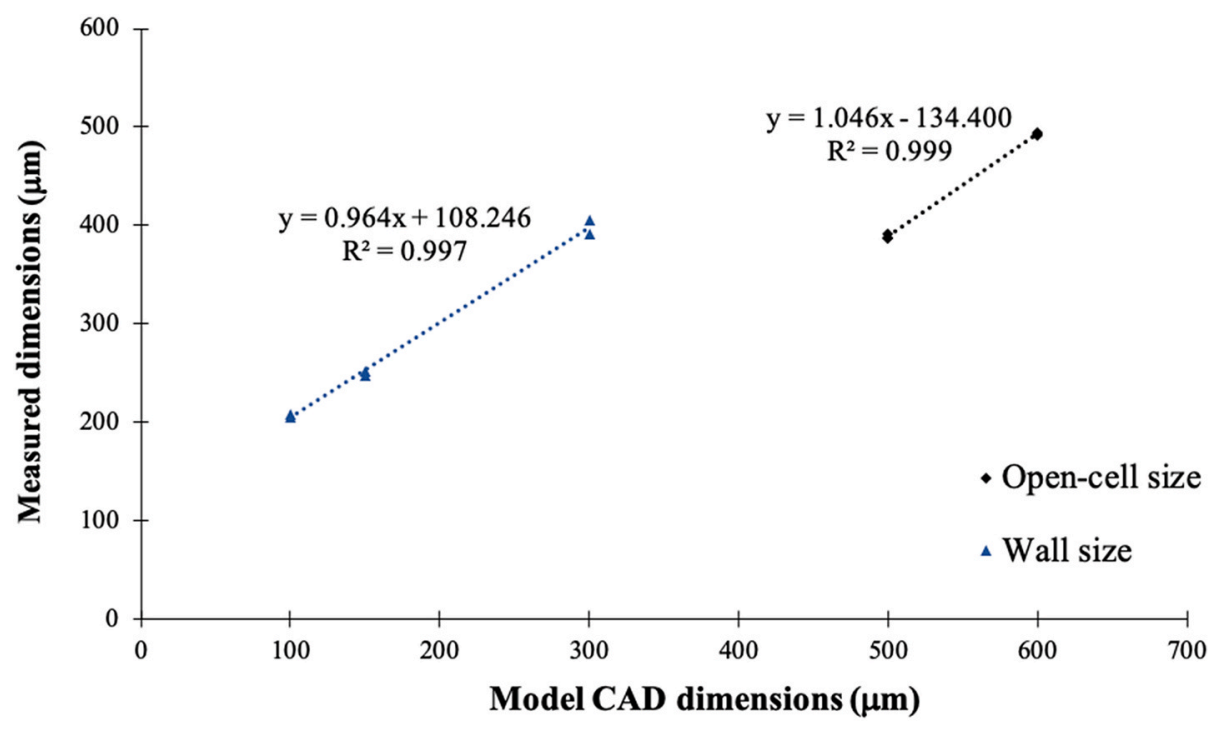

Fig. 7. Linear correlations found for the measured dimensions as a function of the CAD model dimensions. 


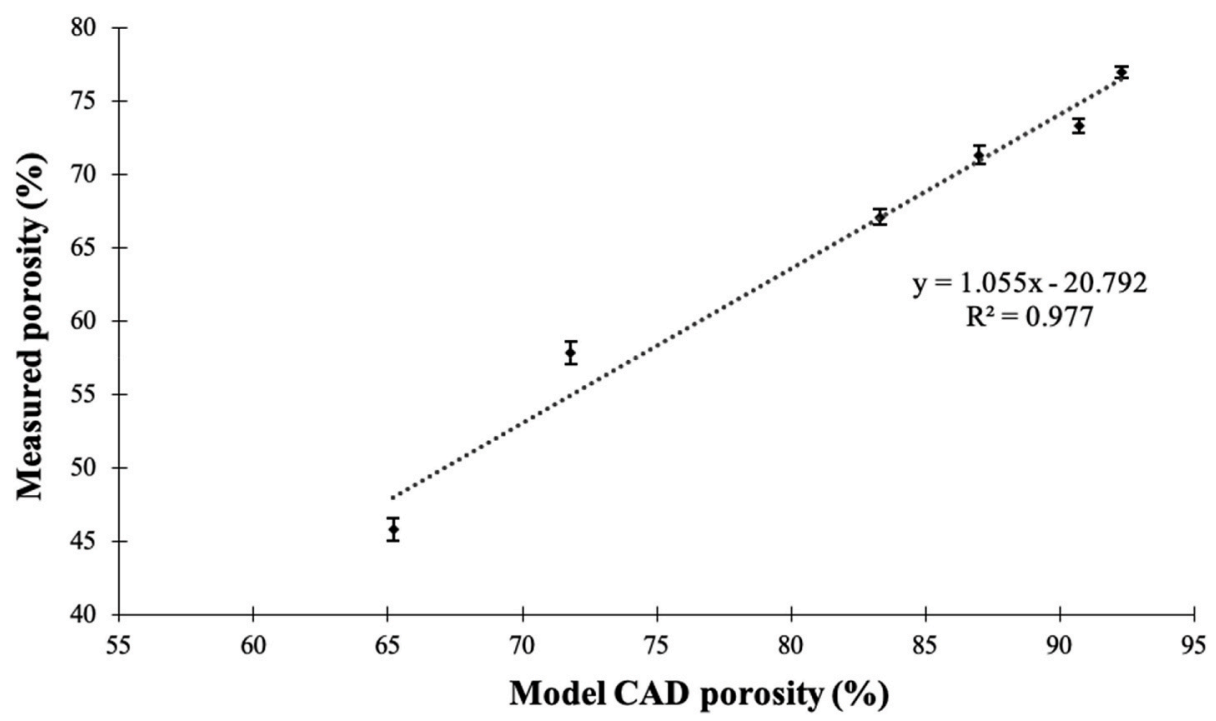

Fig. 8. Linear correlation found for the measured porosity as a function of the CAD model porosity.

open-cells, walls and porosity.

Table 2 shows that all the produced NiTi cellular structures exhibit a lower open-cell size, higher wall size and, consequently, lower porosity compared to their respective CAD models. On average, the SLM NiTi structures have open-cell sizes $\approx 109 \mu \mathrm{m}$ lower and wall sizes $\approx 102 \mu \mathrm{m}$ higher, than the model CAD dimensions. This aspect is predominantly explained by the partial melting of powder in the vicinity of the laser melted zones (dense zones) and the consequent increase of the wall thickness and decrease of the open-cell size (Van Bael et al., 2011). Similar deviations between CAD design and SLM structures have been reported elsewhere, even when using different materials, equipment and processing parameters $(\approx 100 \mu \mathrm{m}$ smaller open-cells and $\approx 100 \mu \mathrm{m}$ thicker walls) (Yan et al., 2015; Zhang et al., 2014; Arabnejad et al., 2016; Ran et al., 2018; Attar et al., 2015). Once the systematic deviations between the CAD model and the produced structures were understood, new CAD models were created (adjusted CADs) using the average dimensions of the open-cells and walls obtained from the morphological analysis. These adjusted CADs were then used to perform finite element analysis to estimate the elastic modulus of these new models/structures and to compare the FEA results with the experimental ones, as shown later.

When designing and fabricating porous structures, the physical and mechanical properties can be tailored by controlling the open-cell and the wall sizes. In this regard, the presence of significant differences between the designed and produced structures have a considerable impact. Looking back at the application of these structures, for orthopaedic implants, where it is necessary to assure suitable physical and mechanical properties to elicit a positive biological outcome, the prediction of these differences is a decisive aspect. In this context, Figs. 7 and 8 show linear correlations found between the CAD model and the produced structures for the dimensions (open-cell and wall sizes) and porosity.

Figs. 7 and 8 show that these linear correlations have high coefficients of determination $\left(\mathrm{R}^{2}>97 \%\right)$ indicating that the observed differences between the CAD design and the SLM NiTi structures exhibit a similar tendency. As reported elsewhere (Yan et al., 2015; Zhang et al., 2014; Arabnejad et al., 2016; Ran et al., 2018; Attar et al., 2015), systematic differences are detected when fabricating porous structures by SLM. The results of the present study indicate that these dimensional deviations were found for all the structures investigated. Above all, it is

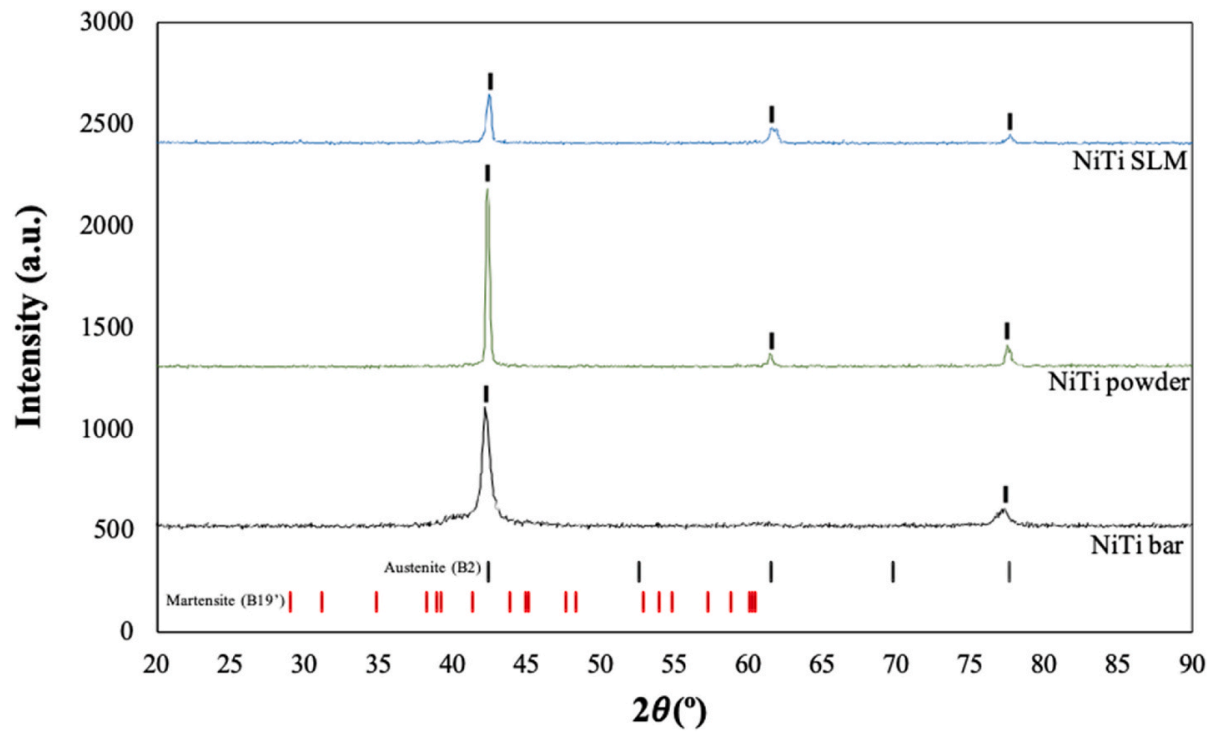

Fig. 9. X-ray diffraction patterns of NiTi bar, NiTi powder, and NiTi SLM structure. (\#03-065-5746-cubic and \#00-035-1281-monoclinic). 


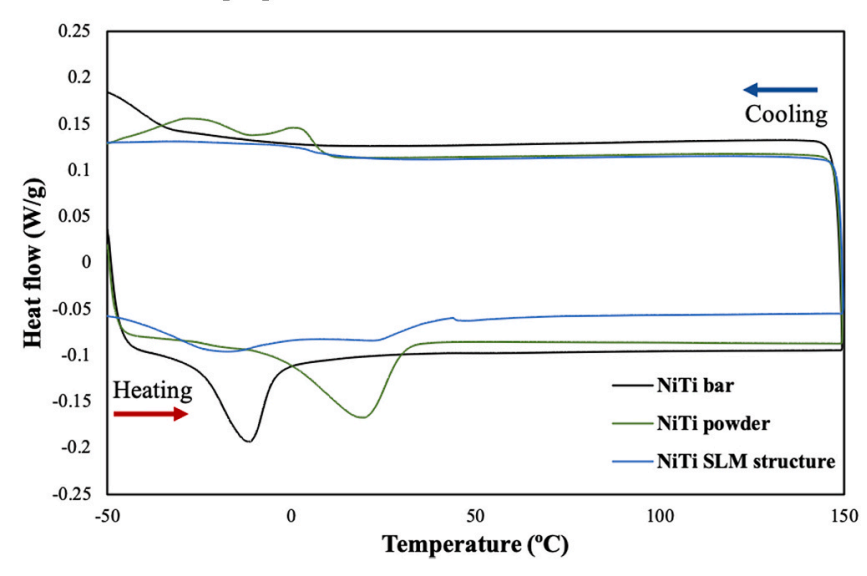

Fig. 10. DSC curves for the NiTi bar, NiTi powder and NiTi SLM structure (SP1).

Table 3

Transformation temperatures $\left({ }^{\circ} \mathrm{C}\right.$ ) of the NiTi bar, NiTi powder, and NiTi SLM structure and the R-phase: (*) R-phase between the austenite and martensite transformation; $\left({ }^{* *}\right)$ R-phase between the martensite and austenite transformation.

\begin{tabular}{llllll}
\hline & $\mathrm{M}_{\mathrm{f}}\left({ }^{\circ} \mathrm{C}\right)$ & $\mathrm{M}_{\mathrm{s}}\left({ }^{\circ} \mathrm{C}\right)$ & $\mathrm{R}_{\mathrm{p}}\left({ }^{\circ} \mathrm{C}\right)$ & $\mathrm{A}_{\mathrm{s}}\left({ }^{\circ} \mathrm{C}\right)$ & $\mathrm{A}_{\mathrm{f}}\left({ }^{\circ} \mathrm{C}\right)$ \\
\hline NiTi bar & $<-50$ & -33.99 & - & -26.01 & -3.79 \\
NiTi powder & $<-50$ & -9.92 & $1.23^{*}$ & -5.98 & 30.47 \\
NiTi SLM & $<-50$ & 12.62 & $-17.27^{* *}$ & -0.72 & 39.16 \\
\hline
\end{tabular}

important to highlight the need and importance of developing guidelines and models (see Figs. 7 and 8) that can help engineers design and obtain desired NiTi cubic-like cellular structures that match the physical and mechanical requirements.

\subsubsection{Crystallographic and thermal analysis}

The X-ray diffraction patterns of the starting NiTi powder, the NiTi bar used for powder atomization and the NiTi structure fabricated by SLM are shown in Fig. 9.

Fig. 9 shows that for all the specimens investigated (NiTi bar, NiTi powder and NiTi SLM structure) the peaks of the XRD patterns indicate the presence of the austenite phase (B2). In fact, the diffraction patterns show a match with the austenite phase's three main peaks at $42.36^{\circ}$ (110), and $77.48^{\circ}(211)$ and $61.46^{\circ}(200)$ considering the XRD card with the reference code of 03-065-5746 (cubic crystal system). These patterns also indicate that there is no evidence of other intermetallics Ni-Ti phases such as, $\mathrm{Ti}_{2} \mathrm{Ni}$ and $\mathrm{Ni}_{4} \mathrm{Ti}_{3}$.

Fig. 10 shows the DSC responses for the $\mathrm{Ni}_{50.8} \mathrm{Ti}_{49.2}$ bar, NiTi powder and NiTi SLM structure, while Table 3 presents the transformation temperatures and $R_{p}$ temperature obtained from the DSC plots which were determined by considering the ASTM F2005 standard (Memry Corporation, 2017).

The transformation temperatures of the NiTi powder and NiTi SLM structure are higher than those found for the NiTi bar. The DSC response of the NiTi powder and the NiTi SLM structures revealed multiple peaks that usually are attributed to inhomogeneous heat transfer and/or compositional inhomogeneity of the powder and also compositional inhomogeneity and R-phase formation (Taheri et al., 2017). The chemical composition analyzes (EDS) carried out on the NiTi parts produced by SLM showed an equiatomic distribution $\left(\mathrm{Ni}_{50} \mathrm{Ti}_{50}\right.$ at. \%) of the alloy. Therefore, when analyzing the chemical composition of the ingot $\left(\mathrm{Ni}_{50.8} \mathrm{Ti}_{49.2}\right.$ at. \%) and the produced parts $\left(\mathrm{Ni}_{50} \mathrm{Ti}_{50}\right.$ at. \%), and compare both analyses with the transformation temperatures, the increase on the TT's of the SLM parts can be attributed to the reduction of the $\mathrm{Ni}$ content ( 0.8 at. \%). In fact, it has been reported that in Ni-rich NiTi (such as the bar used in this study), high-temperature processing (such as powder atomization and SLM) can lead to the formation of $\mathrm{Ni}$

\section{SP2}
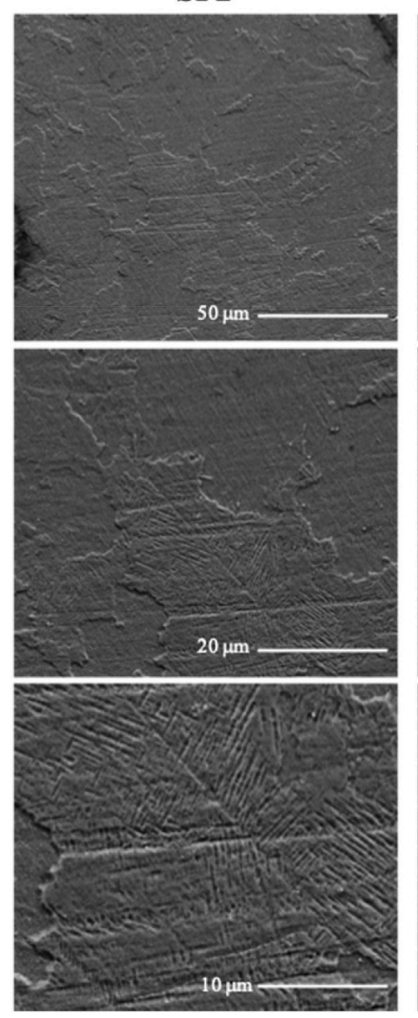

SP3
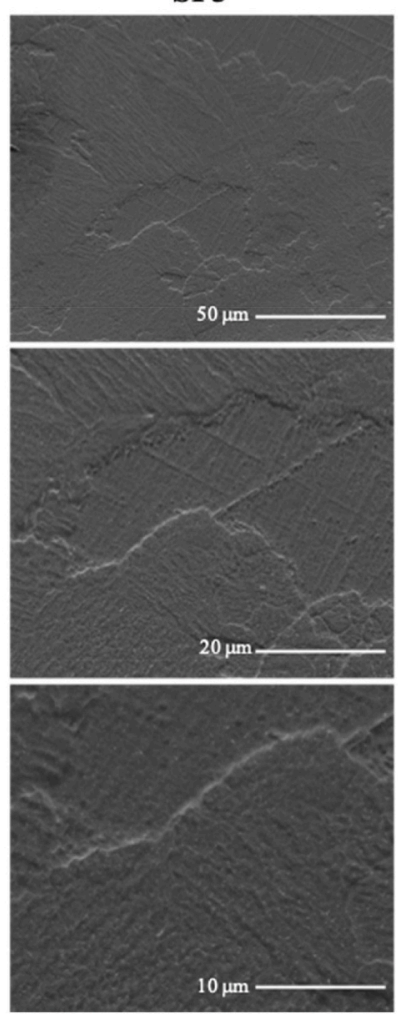

SP4
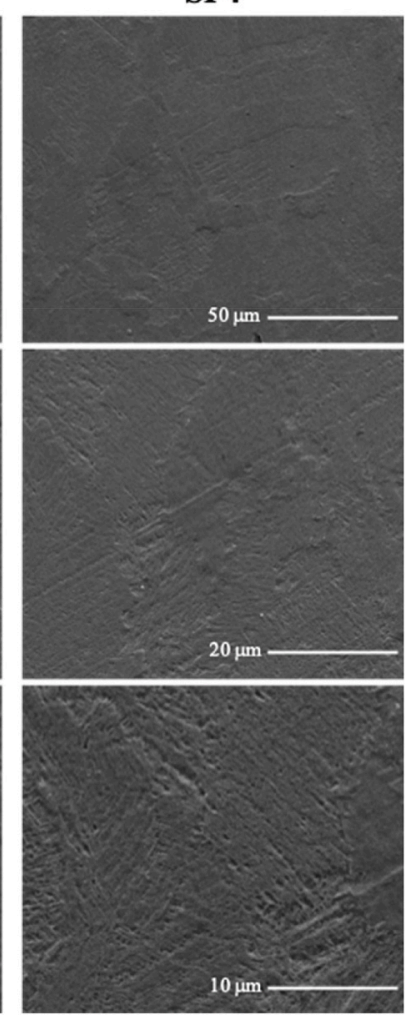

Fig. 11. SEM images of the top surface of NiTi cellular structures produced by SLM after acid-etching (SP1, SP3 and SP4). 


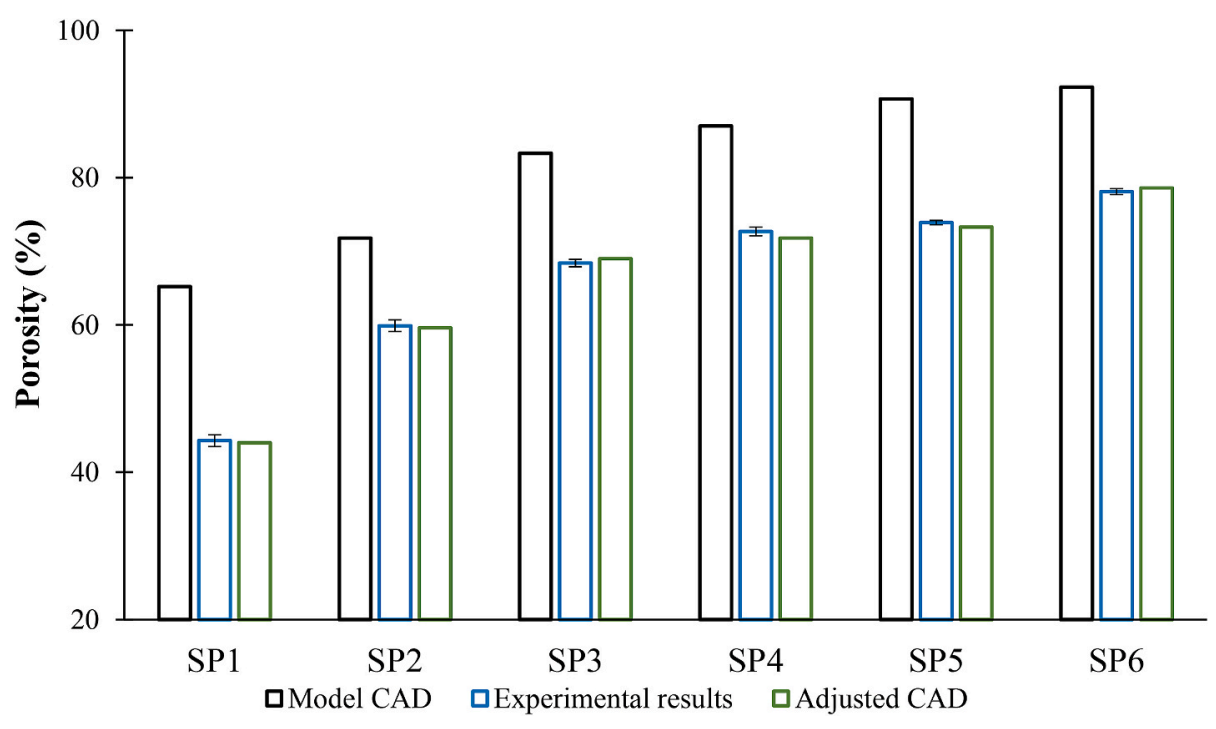

Fig. 12. Porosity of the model CAD, experimental measurements and adjusted CAD.

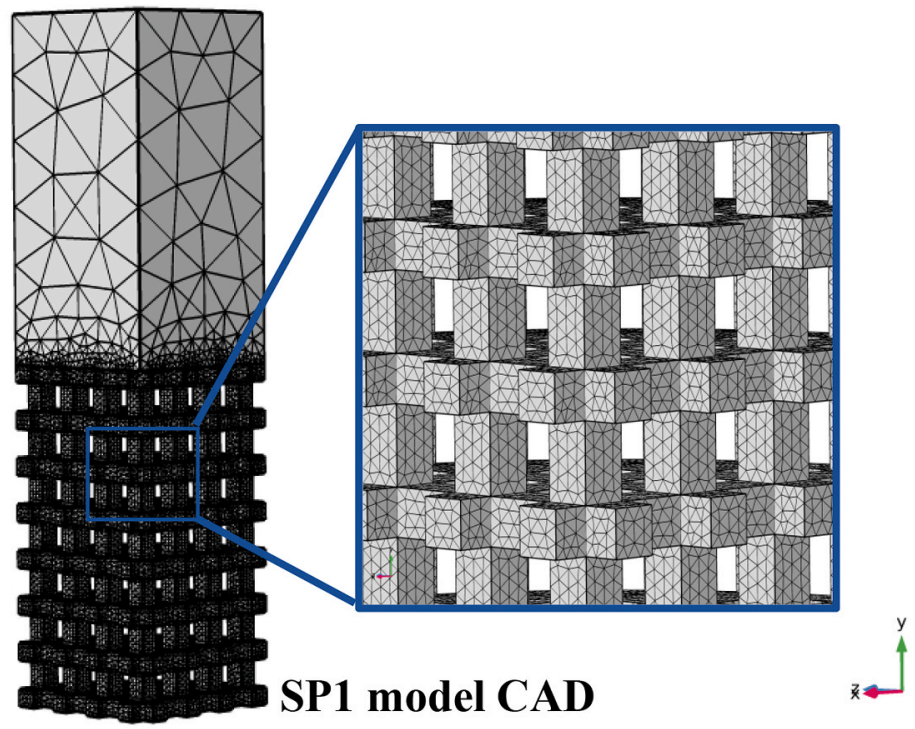

Von Mises stress

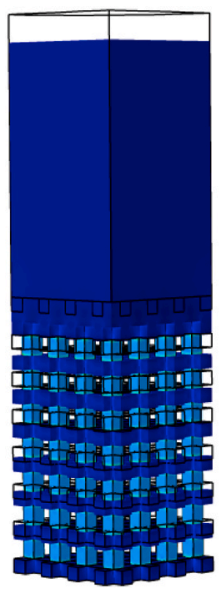

Displacement

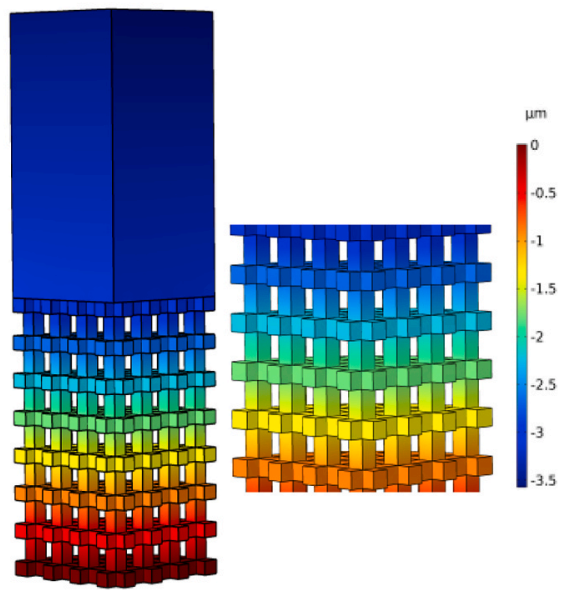

Fig. 13. Mesh and distribution of Von Mises stress and displacement for SP1 model CAD. 


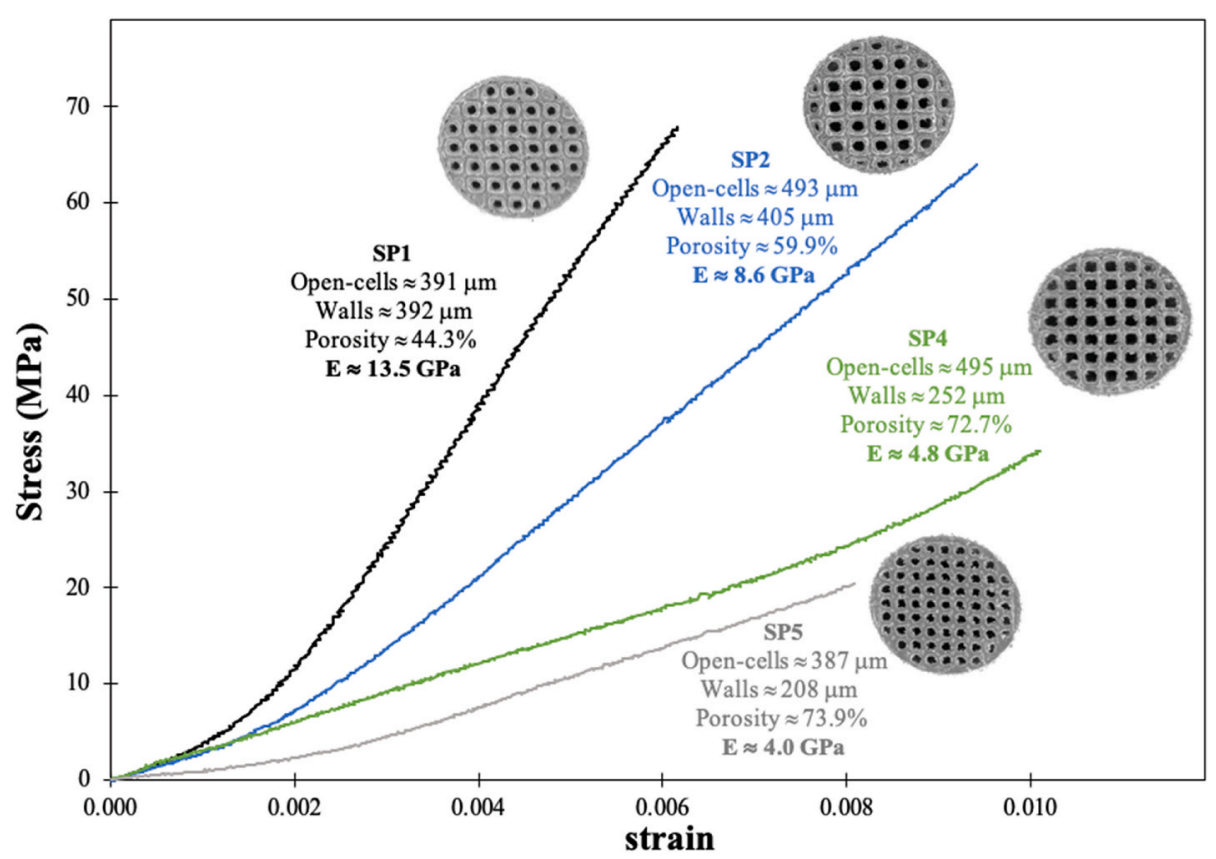

Fig. 14. Representative experimental stress-strain curves showing elastic regions for different NiTi structures with the indication of the average open-cell and wall sizes, and porosity and elastic modulus.

secondary phases and the consequent reduction of the nickel content in the matrix composition (Haberland and Frenzel, 2016). During SLM, the melt pool remains at high temperatures for some time and, during this time, Ni tends to evaporate at a higher rate than Ti due to Ni's lower melting point (Elahinia et al., 2012; Behavior and Melting, 1109; Saedi et al., 2016).

\subsubsection{Microstructural analysis and hardness}

A strong relationship exists between the SLM process, the microstructure and the mechanical properties of the resulting components. The processing parameters and the heat transfer play a big role on the densification, microstructure, texture, and anisotropy of the SLM parts (Lewandowski and Seifi, 2016). In this study, the top surfaces of cylindrical NiTi structures were mirror-polished followed by acid etching using a solution prepared with $\mathrm{H}_{2} \mathrm{O}, \mathrm{HNO}_{3}$ and HF. Fig. 11 shows SEM images with three different magnifications of SP3 as an example of the typical microstructure found for the NiTi produced structures. The microstructure of the SLM-produced NiTi structures depicts some grain boundaries similar to those reported elsewhere (Shishkovsky et al., 2012).

Micro-hardness tests were also performed on the produced NiTi structures and the results were very similar for all the produced NiTi structures. The results were $297 \pm 6,310 \pm 4,302 \pm 7,303 \pm 5,303 \pm$ 10 and $307 \pm 7$ HV for SP1, SP2, SP3, SP4, and SP5, respectively. The average hardness values varied from 297 to $310 \mathrm{HV}$, which indicates that, for these processing parameters, the production of NiTi structures with different open-cell and wall sizes and porosities has no significant effect on the hardness.

\subsection{Elastic modulus assessment and correlation models}

Currently, conventional hip implants are usually made of dense

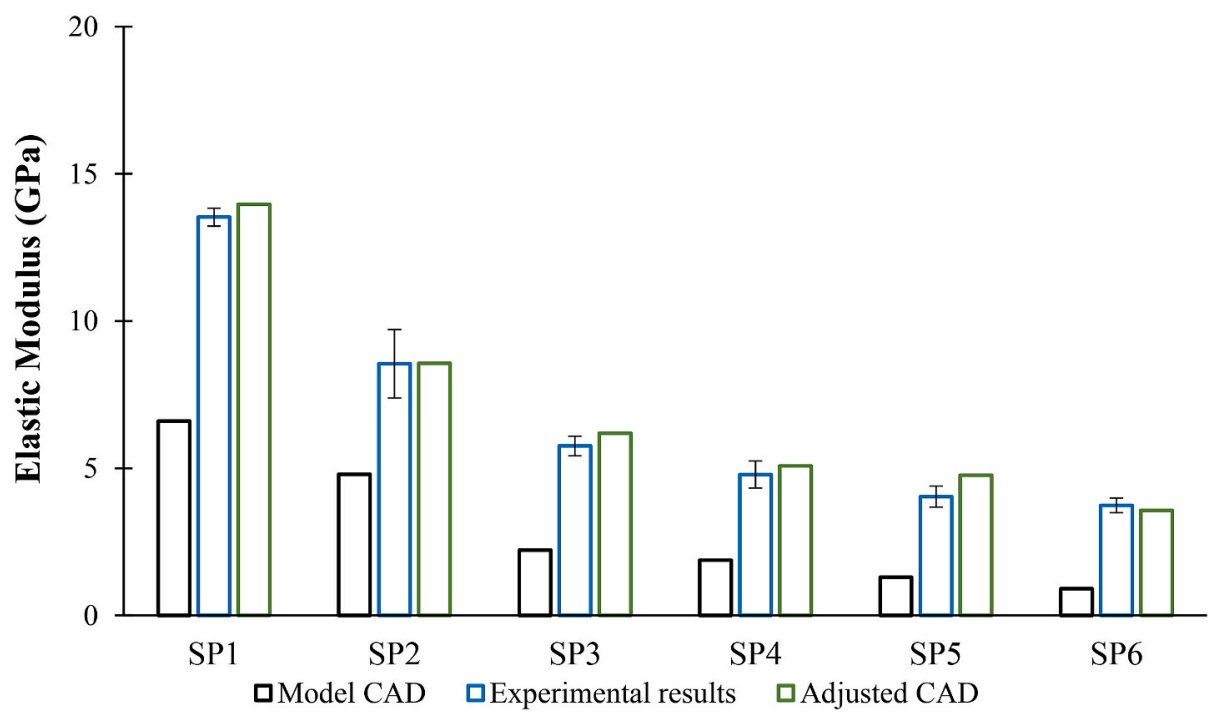

Fig. 15. Elastic modulus of the SLM-produced NiTi structures (experimental results) and the finite element analysis (model CAD and adjusted CAD). 


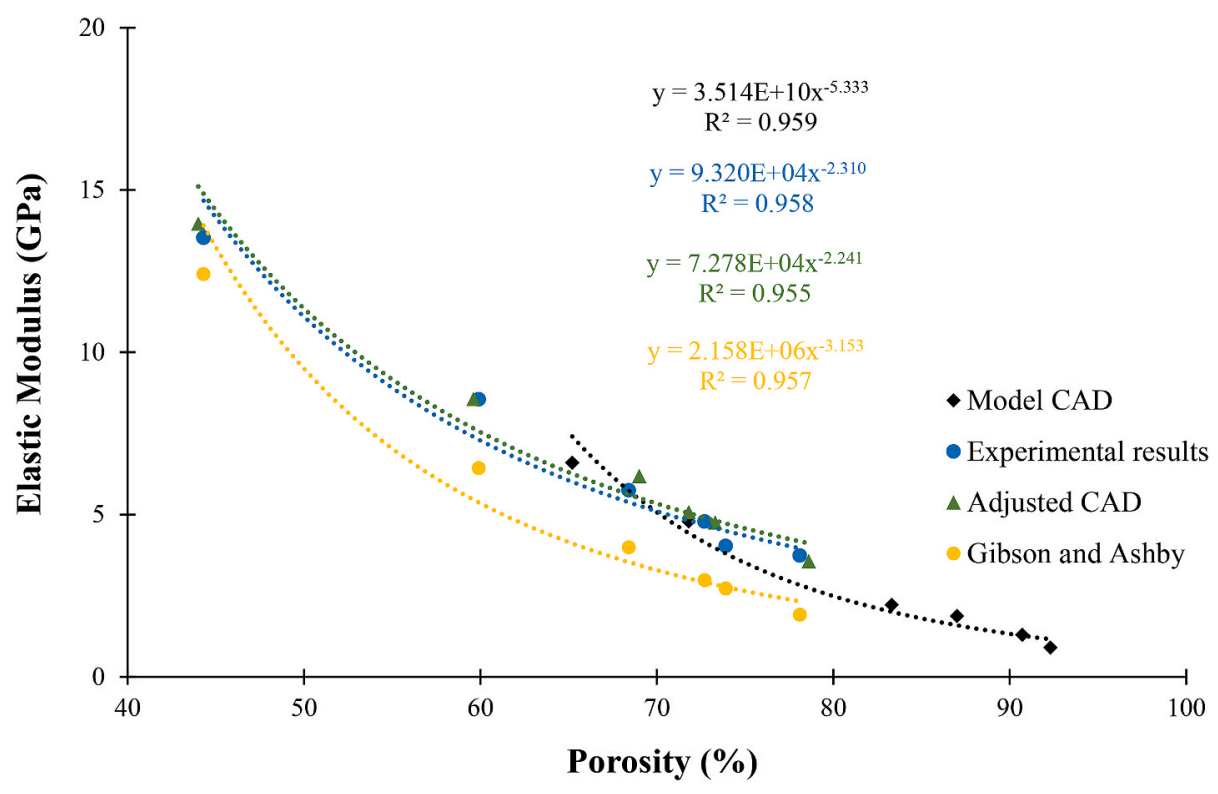

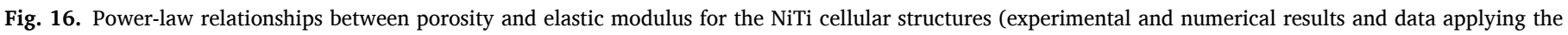
Gibson-Ashby power-law (Equation (2)).

materials such as Ti6Al4V alloy. Despite the developments in this area, the solutions available on the market are known to have a limited lifetime. Dense implants are known to induce stress shielding and, typically, aggressive revision surgeries are necessary 10-15 years after Total Hip Arthroplasty (Behavior and Melting, 1109). To address this problem, NiTi cellular structures with different levels of porosity were designed, SLM fabricated and mechanically tested to propose advanced implant solutions. Fig. 12 shows the porosity measured on the SLM-produced NiTi structures (experimental results) and the porosities corresponding to the initial CAD model and the adjusted CAD.

Fig. 12 shows that all the SLM-produced NiTi structures have a lower porosity than the designed CAD model. This aspect is related to the systematically narrower open-cells and thicker walls found for all the NiTi structures, as shown in Table 2. Moreover, Fig. 12 shows that only very slight differences were found when comparing the experimentally measured porosity with the adjusted CAD porosities. This aspect indicates that the adopted image analysis methodology satisfactorily reproduced the produced NiTi structures.

Fig. 13 depicts the Von Mises stress and displacement distributions for the FEA performed on the SP1 CAD model. The Von-Mises stress plots show a clear indication of normally distributed stresses along the height of the specimen. The geometrical discontinuities of the structures (occurring on the intersections of the walls) exhibit a higher stress magnitude due to stress concentration. With respect to the displacement, the plots show homogenous and coherent distributions, indicating that no singularities are present on the models. The elastic modulus results obtained by FEA for the adjusted CAD exhibit a suitable agreement with the experimental results (see Figs. 15 and 16).

In Fig. 14 can be seen experimental representative stress-strain curves showing the elastic regions for different NiTi structures (SP1, SP2, SP4, and SP5) under compressive testing. Typically, compressive stress-strain curves of porous structures consist of three parts, starting with the elastic domain until the first peak, corresponding to the compressive strength, followed by the plateau region and, finally a densification region (Hernández-Nava et al., 2015; Li et al., 2014). The present work is focused on the relation between the porosity of NiTi cellular structures and the elastic modulus and thus, Fig. 14 compares representative stress-strain curves of the linear elastic domain, for different typologies of structures, that were used to estimate the average elastic modulus (see Fig. 15). Considering the cubic-like architecture of the NiTi cellular structures it is perceptible that exists a compromising relation between the open-cell and the wall sizes on the porosity and consequently on the elastic modulus. For structures with higher wall sizes (SP1 and SP2), the effect of the open-cell size on the porosity and consequently on the elastic modulus is more pronounced than that observed for lower walls sizes (SP3-SP6). When analysing Fig. 14, a gradual decrease in the slope of the stress-strain can be observed when decreasing the porosity of the NiTi structures which results in lower elastic modulus values. Fig. 15 where the relation between the elastic modulus obtained experimentally for the SLM structures and numerically for the CAD models and the adjusted CADs. As a consequence of the differences obtained for the porosity (Fig. 12), lower elastic moduli were obtained for all the CAD model designs compared to the experimentally obtained elastic modulus.

The elastic modulus of the CAD models varied from 0.9 to $6.6 \mathrm{GPa}$, while the experimentally obtained elastic modulus varied from 3.7 to 13.5 GPa. The elastic modulus obtained for the adjusted CAD designs were only slightly different $(\approx 4 \%)$ compared to the experimental results. These results are a good indication of the effectiveness of the proposed methodology to replicate the NiTi structures.

These NiTi structures can be further considered for designing structures with a specific elastic modulus suitable for each patient's bone properties, which can be obtained by tomography or magnetic resonance imaging 3D data (Chen and Thouas, 2015; Yan et al., 2015; Ryan et al., 2006; Thavornyutikarn et al., 2014). Several studies reported the success of cellular structures to reduce stress shielding and bone resorption by employing a lower stiffness (lower elastic modulus) that better approximates the cortical bone elastic modulus (10-30 GPa) (Geetha et al., 2009; Dallago et al., 2018).

Many efforts have been made to model the dependence of mechanical properties on the porosity of engineering porous materials. Based on experimental results, a number of models have been proposed to represent the relationship between elastic modulus and porosity taking into consideration the porosity content and the architecture of the porous materials ( $G$ and Ashby, 1982). The relationship between elastic modulus and the porosity content in porous materials is described through a power-law. Gibson and Ashby's models estimated a power-law fit for the relation between the elastic modulus and the porosity of porous materials as follows ( $G$ and Ashby, 1982):

$$
\frac{E}{E_{0}}=C\left(\frac{\rho}{\rho_{0}}\right)^{n}=C(1-\rho)^{n}
$$


where $E_{0}$ is the elastic modulus of the bulk material, and $C$ and $n$ are constants that depend on the microstructure. For cellular structures with a dense solid network, $\mathrm{C}=1$, while in other cases, this constant can assume different values and the exponent $n$ has a value in the range of $1-4$, with $n=2$ for open-cell structures ( $G$ and Ashby, 1982). In the present study the NiTi cubic-like cellular structures can be approximated as open-cell structures in which the solid network (walls) is fully dense; therefore, $\mathrm{C}=1$ and $\mathrm{n}=2$ and Equation (1) can be rewritten as:

$E=E_{0}(1-p)^{2}$

where $p$ is the porosity of the NiTi structures and $E_{0}$ is the NiTi alloy elastic modulus.

Fig. 16 shows the correlations between the porosity and the elastic modulus, both for the experimental and numerical approaches carried out in this study. The power-law fit by Gibson and Ashby is also included for comparison purposes. The power-law correlations for the experimental, the numerical and the Gibson and Ashby's model, show high coefficients of determination $\left(\mathrm{R}^{2}>95 \%\right)$ indicating a good fit using power laws for the model CAD, experimental results and adjusted CAD. It can be mentioned that in some extension the obtained experimental results are aligned with the predicted models of Gibson and Ashby for porous materials. Moreover, the experimental results curve and the adjusted $\mathrm{CAD}$ results curve are very similar, almost overlapping.

The reported differences between the CAD model and the experimental results (for the porosity and the elastic modus) and the correlations presented in Fig. 16 can be used as design guidelines that integrate SLM's inherent deviations. By doing so, engineers can design NiTi structures that display the intended porosity and elastic modulus after fabrication.

\section{Conclusions}

- Cubic-like NiTi cellular structures with different levels of porosity were designed and fabricated by SLM;

- Experimental and numerical approaches were carried out to obtain the elastic modulus of NiTi structures;

- Non-negligible differences were systematically found between the CAD design and the SLM-produced NiTi structures;

- Adjusted designs were created to reproduce the dimensions and geometries of the SLM-produced NiTi structures;

- The numerical elastic modulus results of the adjusted designs show good agreement with the experimental results;

- Design tools are proposed to anticipate the real dimensions and porosity of SLM-produced NiTi cellular structures;

- The produced NiTi structures exhibit elastic moduli that match that of bone tissue, indicating the suitability of these structures for orthopaedic implants.

\section{Acknowledgements}

This work was supported by FCT (Fundação para a Ciência e Tecnologia) through the grant SFRH/BD/128657/2017 and the projects POCI-01-0145-FEDER-030353 (SMARTCUT), NORTE 01-0145_FEDER000018-HAMaBICo, UID/EEA/04436/2019 and UID/Multi/04044/ 2019.

\section{References}

Arabnejad, S., Johnston, R.B., Ann, J., Singh, B., Tanzer, M., Pasini, D., 2016. Highstrength porous biomaterials for bone replacement : a strategy to assess the interplay between cell morphology, mechanical properties, bone ingrowth and manufacturing constraints. Acta Biomater. 30, 345-356. https://doi.org/10.1016/j. actbio.2015.10.048.

Attar, H., Löber, L., Funk, A., Calin, M., Zhang, L.C., Prashanth, K.G., Scudino, S., Zhang, Y.S., Eckert, J., 2015. Mechanical behavior of porous commercially pure Ti and Ti-TiB composite materials manufactured by selective laser melting. Mater. Sci. Eng. A 625, 350-356. https://doi.org/10.1016/j.msea.2014.12.036.
Van Bael, S., Kerckhofs, G., Moesen, M., Pyka, G., Schrooten, J., Kruth, J.P., 2011. MicroCT-based improvement of geometrical and mechanical controllability of selective laser melted Ti6Al4V porous structures. Mater. Sci. Eng. A 528, 7423-7431. https:// doi.org/10.1016/j.msea.2011.06.045.

Van Bael, S., Chai, Y.C., Truscello, S., Moesen, M., Kerckhofs, G., Van Oosterwyck, H., 2012. Acta Biomaterialia the effect of pore geometry on the in vitro biological behavior of human periosteum-derived cells seeded on selective laser-melted Ti6Al4V bone scaffolds. Acta Biomater. 8, 2824-2834. https://doi.org/10.1016/j. actbio.2012.04.001.

Bartolomeu, F., Faria, S., Carvalho, O., Pinto, E., Alves, N., Silva, F.S., Miranda, G., 2016. Predictive models for physical and mechanical properties of Ti6Al4V produced by Selective Laser Melting. Mater. Sci. Eng. A 663, 181-192. https://doi.org/10.1016/j. msea.2016.03.113.

Bartolomeu, F., Abreu, C.S., Moura, C.G., Costa, M.M., Alves, N., Silva, F.S., Miranda, G., 2018a. Ti6Al4V-PEEK multi-material structures - design, fabrication and tribological characterization focused on orthopedic implants. Tribol. Int. 131, 672-678. https:// doi.org/10.1016/j.triboint.2018.11.017.

Bartolomeu, F., Costa, M.M., Gomes, J.R., Alves, N., Abreu, C.S., Silva, F.S., Miranda, G., 2018b. Implant surface design for improved implant stability - a study on Ti6Al4V dense and cellular structures produced by Selective Laser Melting. Tribol. Int. https://doi.org/10.1016/j.triboint.2018.08.012.

Bartolomeu, F., Buciumeanu, M., Costa, M.M., Alves, N., Gasik, M., Silva, F.S., Miranda, G., 2019a. Multi-material Ti6Al4V \& PEEK cellular structures produced by Selective Laser Melting and Hot Pressing : a tribocorrosion study targeting orthopedic applications. J. Mech. Behav. Biomed. Mater. 89, 54-64. https://doi.org/ 10.1016/j.jmbbm.2018.09.009.

Bartolomeu, F., Fonseca, J., Peixinho, N., Alves, N., Gasik, M., Silva, F.S., Miranda, G., $2019 \mathrm{~b}$. Predicting the output dimensions, porosity and elastic modulus of additive manufactured biomaterial structures targeting orthopedic implants. J. Mech. Behav. Biomed. Mater. 99, 104-117. https://doi.org/10.1016/j.jmbbm.2019.07.023.

Bartolomeu, F., Dourado, N., Pereira, F., Alves, N., Miranda, G., Silva, F.S., 2020. Additive manufactured porous biomaterials targeting orthopedic implants: a suitable combination of mechanical, physical and topological properties. Mater. Sci. Eng. C 107, 110342. https://doi.org/10.1016/j.msec.2019.110342.

T. Behavior, L. Melting, A Short Review on the Microstructure, Transformation Behavior and Functional Properties of NiTi Shape Memory Alloys Fabricated by Selective, (n. d.). doi:10.3390/ma11091683.

Bose, S., Ke, D., Sahasrabudhe, H., Bandyopadhyay, A., 2018. Progress in materials science additive manufacturing of biomaterials. Prog. Mater. Sci. 93, 45-111. https://doi.org/10.1016/j.pmatsci.2017.08.003.

Buciumeanu, M., Almeida, S., Bartolomeu, F., Costa, M.M., Alves, N., Silva, F.S., Miranda, G., 2018. Ti6Al4V cellular structures impregnated with biomedical PEEK new material design for improved tribological behavior. Tribol. Int. 119, 157-164. https://doi.org/10.1016/j.triboint.2017.10.038.

Capek, J., Machová, M., Fousová, M., Kubbásek, J., Vojtechch, D., Fojt, J., Jablonská, E., Lipov, J., Ruml, T., 2016. Highly porous, low elastic modulus 316L stainless steel scaffold prepared by selective laser melting. Mater. Sci. Eng. C 69, 631-639. https:// doi.org/10.1016/j.msec.2016.07.027.

Chen, Q., Thouas, G.A., 2015. Metallic implant biomaterials. Mater. Sci. Eng. R Rep. 87, 1-57. https://doi.org/10.1016/j.mser.2014.10.001.

Chen, S.Y., Huang, J.C., Pan, C.T., Lin, C.H., Yang, T.L., Huang, Y.S., Ou, C.H., Chen, L.Y., Lin, D.Y., Lin, H.K., Li, T.H., Jang, J.S.C., Yang, C.C., 2017. Microstructure and mechanical properties of open-cell porous Ti-6Al- 4V fabricated by selective laser melting, 713, 248-254. https://doi.org/10.1016/j.jallcom.2017.04.190.

Dadbakhsh, S., Speirs, M., Kruth, J., Van Humbeeck, J., 2015. CIRP Annals manufacturing Technology Influence of SLM on shape memory and compression behaviour of NiTi scaffolds. CIRP Ann. - Manuf. Technol. 64, 209-212. https://doi. org/10.1016/j.cirp.2015.04.039.

Dallago, M., Fontanari, V., Torresani, E., Leoni, M., Pederzolli, C., Potrich, C., Benedetti, M., 2018. Fatigue and biological properties of Ti-6Al-4V ELI cellular structures with variously arranged cubic cells made by selective laser melting. J. Mech. Behav. Biomed. Mater. 78, 381-394. https://doi.org/10.1016/j. jmbbm.2017.11.044.

Elahinia, M.H., Hashemi, M., Tabesh, M., 2012. Progress in materials science manufacturing and processing of NiTi implants : A review, 57, 911-946. https://doi. org/10.1016/j.pmatsci.2011.11.001.

Fousová, M., Vojt, D., Jablonská, E., Fojt, J., 2017. Characteristics of gradient porosity Ti6Al-4V alloy prepared by SLM process. J. Mech. Behav. Biomed. Mater. 69, 368-376. https://doi.org/10.1016/j.jmbbm.2017.01.043.

G, I.J., Ashby, M.F., 1982. The mechanics of three-dimensional cellular materials. Proc. Roy. Soc. Lond. A. 382, 43-59.

Geetha, M., Singh, A.K., Asokamani, R., Gogia, A.K., 2009. Ti based biomaterials, the ultimate choice for orthopaedic implants - a review. Prog. Mater. Sci. 54, 397-425. https://doi.org/10.1016/j.pmatsci.2008.06.004.

C. Haberland, J. Frenzel, SMASIS2012-8040, (2016) 1-8.

Hamilton, R.F., Bimber, B.A., Taheri, M., Elahinia, M., 2017. Multi-scale shape memory e ff ect recovery in NiTi alloys additive manufactured by selective laser melting and laser directed energy deposition. J. Mater. Process. Technol. 250, 55-64. https://doi. org/10.1016/j.jmatprotec.2017.06.027.

Hernández-Nava, E., Smith, C.J., Derguti, F., Tammas-Williams, S., Léonard, F., Withers, P.J., Todd, I., Goodall, R., 2015. The effect of density and feature size on mechanical properties of isostructural metallic foams produced by additive manufacturing. Acta Mater. 85, 387-395. https://doi.org/10.1016/j. actamat.2014.10.058.

Holzwarth, U., Cotogno, G., 2012. Total hip arthroplasty. https://doi.org/10.2788/ 31286. 
Van Hooreweder, B., Apers, Y., Lietaert, K., Kruth, J.P., 2017. Improving the fatigue performance of porous metallic biomaterials produced by Selective Laser Melting. Acta Biomater. 47, 193-202. https://doi.org/10.1016/j.actbio.2016.10.005.

A. Jahadakbar, N.S. Moghaddam, A. Amerinatanzi, Finite Element Simulation and Additive Manufacturing of Stiffness-Matched NiTi Fixation Hardware for Mandibular Reconstruction Surgery, (n.d.) 1-20. doi:10.3390/bioengineering3040036.

Karageorgiou, V., Kaplan, D., 2005. Porosity of 3D biomaterial scaffolds and osteogenesis. Biomaterials 26, 5474-5491. https://doi.org/10.1016/j. biomaterials.2005.02.002.

Kumar, A., Mandal, S., Barui, S., Vasireddi, R., Gbureck, U., Gelinsky, M., Basu, B., 2016. Low temperature additive manufacturing of three dimensional scaffolds for bonetissue engineering applications: processing related challenges and property assessment. Mater. Sci. Eng. R Rep. 103, 1-39. https://doi.org/10.1016/j. mser.2016.01.001.

Lewandowski, J.J., Seifi, M., 2016. Metal additive manufacturing: a review of mechanical properties. Annu. Rev. Mater. Res. 46, 151-186. https://doi.org/ 10.1146/annurev-matsci-070115-032024.

Li, S.J., Xu, Q.S., Wang, Z., Hou, W.T., Hao, Y.L., Yang, R., Murr, L.E., 2014. Influence of cell shape on mechanical properties of Ti-6Al-4V meshes fabricated by electron beam melting method. Acta Biomater. 10, 4537-4547. https://doi.org/10.1016/j. actbio.2014.06.010.

Liu, S., Shin, Y.C., 2019. Additive manufacturing of Ti6Al4V alloy : a review. Mater. Des. 164, 107552. https://doi.org/10.1016/j.matdes.2018.107552.

Memry Corporation, 2017. Introduction to nitinol. https://daks2k3a4ib2z.cloudfront. net/59fcbaf103e295000131288b/5a4bb3895344bc000191bac9_Introduction to Nitinol_V5.pdf.

Miranda, G., Faria, S., Bartolomeu, F., Pinto, E., Alves, N., Peixinho, N., Gasik, M., Silva, F.S., 2019. A study on the production of thin-walled Ti6Al4V parts by selective laser melting. J. Manuf. Process. 39, 346-355. https://doi.org/10.1016/j. jmapro.2018.12.036.

Moura, C.G., Pereira, R., Buciumeanu, M., Carvalho, O., Bartolomeu, F., Nascimento, R. Silva, F.S., 2017. Effect of laser surface texturing on primary stability and surface properties of zirconia implants. Ceram. Int. 43, 15227-15236. https://doi.org/ 10.1016/j.ceramint.2017.08.058.

Moura, C.G., Carvalho, O., V Gonçalves, L.M., Cerqueira, M.F., Nascimento, R., Silva, F., 2019. Materials Science \& Engineering C Laser surface texturing of Ti-6Al-4V by nanosecond laser : surface characterization, Ti-oxide layer analysis and its electrical insulation performance. Mater. Sci. Eng. C 104, 109901. https://doi.org/10.1016/j. msec.2019.109901.

Rahimizadeh, A., Nourmohammadi, Z., Arabnejad, S., Tanzer, M., Pasini, D., 2018. Porous architected biomaterial for a tibial-knee implant with minimum bone resorption and bone-implant interface micromotion. J. Mech. Behav. Biomed. Mater. 78, 465-479. https://doi.org/10.1016/j.jmbbm.2017.11.041.

Ran, Q., Yang, W., Hu, Y., Shen, X., Yu, Y., Xiang, Y., Cai, K., 2018. Osteogenesis of 3D printed porous Ti6Al4V implants with different pore sizes. J. Mech. Behav. Biomed. Mater. 84, 1-11. https://doi.org/10.1016/j.jmbbm.2018.04.010.
Ryan, G., Pandit, A., Apatsidis, D.P., 2006. Fabrication methods of porous metals for use in orthopaedic applications. Biomaterials 27, 2651-2670. https://doi.org/10.1016/ j.biomaterials.2005.12.002.

Saedi, S., Turabi, A.S., Andani, M.T., Haberland, C., Karaca, H., Elahinia, M., 2016. The influence of heat treatment on the thermomechanical response of Ni-rich NiTi alloys manufactured by selective laser melting. J. Alloys Compd. 677, 204-210. https:// doi.org/10.1016/j.jallcom.2016.03.161.

Shishkovsky, I., Yadroitsev, I., Smurov, I., 2012. Direct selective laser melting of nitinol powder, 39, 447-454. https://doi.org/10.1016/j.phpro.2012.10.060.

Speirs, M., Van Hooreweder, B., Van Humbeeck, J., Kruth, J., 2017. Journal of the Mechanical Behavior of Biomedical Materials Fatigue behaviour of NiTi shape memory alloy sca ff olds produced by SLM , a unit cell design comparison. J. Mech. Behav. Biomed. Mater. 70, 53-59. https://doi.org/10.1016/j.jmbbm.2017.01.016.

Taheri, M., Saedi, S., Sadi, A., Karamooz, M.R., 2017. Mechanical and shape memory properties of porous Ni50.1Ti49.9 alloys manufactured by selective laser melting. J. Mech. Behav. Biomed. Mater. 68, 224-231. https://doi.org/10.1016/j. jmbbm.2017.01.047.

Thavornyutikarn, B., Chantarapanich, N., Chen, Q., 2014. Bone Tissue Engineering Scaffolding : Computer-Aided Scaffolding Techniques. https://doi.org/10.1007/ s40204-014-0026-7.

Toptan, F., Alves, A.C., Carvalho, Ó., Bartolomeu, F., Pinto, A.M.P., Silva, F., Miranda, G., 2019. Corrosion and tribocorrosion behaviour of Ti6Al4V produced by selective laser melting and hot pressing in comparison with the commercial alloy. J. Mater Process. Technol. 266, 239-245. https://doi.org/10.1016/j. jmatprotec.2018.11.008.

Wang, X., Xu, S., Zhou, S., Xu, W., Leary, M., Choong, P., Qian, M., Brandt, M., Xie, Y.M., 2016. Topological design and additive manufacturing of porous metals for bone scaffolds and orthopaedic implants: a review. Biomaterials 83, 127-141. https://doi. org/10.1016/j.biomaterials.2016.01.012.

Yan, C., Hao, L., Hussein, A., Young, P., 2015. Ti-6Al-4V triply periodic minimal surface structures for bone implants fabricated via selective laser melting. J. Mech. Behav. Biomed. Mater. 51, 61-73. https://doi.org/10.1016/j.jmbbm.2015.06.024.

Yang, Y., Zhan, J.B., Li, B., Lin, J.X., Gao, J.J., Zhang, Z.Q., Ren, L., Castany, P., Gloriant, T., 2019. Laser beam energy dependence of martensitic transformation in slm fabricated niti shape memory alloy, 6. https://doi.org/10.1016/j. mtla.2019.100305.

Zhang, X., Wei, L., 2019. Journal of the Mechanical Behavior of Biomedical Materials Processing and damping capacity of NiTi foams with laminated pore architecture. J. Mech. Behav. Biomed. Mater. 96, 108-117. https://doi.org/10.1016/j. jmbbm.2019.04.036.

Zhang, S., Wei, Q., Cheng, L., Li, S., Shi, Y., 2014. Effects of scan line spacing on pore characteristics and mechanical properties of porous Ti6Al4V implants fabricated by selective laser melting, 63, 185-193. https://doi.org/10.1016/j. matdes.2014.05.021.

Zhou, Q., Dilawer, M., Chen, G., Cai, S., Qu, X., 2019. Materials Science \& Engineering A Selective electron beam melting of NiTi : microstructure, phase transformation and mechanical properties. Mater. Sci. Eng. A 744, 290-298. https://doi.org/10.1016/j. msea.2018.12.023. 